\title{
Effect of Intratympanic Application of Aminoglycosides on Click-Evoked Myogenic Potentials in Guinea Pigs
}

\author{
An-Shiou Day, June-Horng Lue, Ting-Hua Yang, and Yi-Ho Young
}

\begin{abstract}
Objectives: Although numerous studies have identified damage to the cochlear and vestibular end organs as the primary site of aminoglycoside-induced ototoxicity, the effect on the saccule remains poorly understood, possibly due to lack of monitoring saccular function in experimental animals. Therefore, this study applied three kinds of aminoglycosides into the tympanic space of guinea pigs to examine their toxic impact on the saccule by way of click-evoked myogenic potential test coupled with morphologic assessment.
\end{abstract}

Design: Albino guinea pigs were treated with saline, gentamicin, tobramycin, or amikacin, with 10 animals assigned to each group. Each compound was injected directly overlying but not through the round window membrane on the left ear, with the right ear serving as a control. One week after injection, each animal underwent auditory brain stem response, caloric test, and click-evoked myogenic potential test. Animals were then killed for morphologic assessment through the use of light and electron microscopic examinations.

Results: The animals treated with saline, gentamicin, tobramycin, or amikacin exhibited abnormal auditory brain stem response in $0 \%, 30 \%, 100 \%$, and $30 \%$ of cases; abnormal caloric responses were found in $0 \%, 100 \%, 40 \%$, and $40 \%$ of cases; absent clickevoked myogenic potentials were found in $0 \%, 100 \%$, $30 \%$, and $40 \%$ of cases, respectively. Gentamicin and other groups differed significantly in abnormal rates of caloric responses and click-evoked myogenic potentials. Morphologic study of the gentamicin-treated animals confirmed that the absence of click-evoked myogenic potential originated from the lesion in the saccular macula.

Conclusions: Gentamicin represents the dominant susceptibility of aminoglycoside-induced vestibulotoxicity for eliminating both semicircular canal and saccular functions. This study further confirms the findings of human studies in which the caloric and vestibular evoked myogenic potentials responses were monitored to assess the abolition of vestibular

Department of Otolaryngology (A.-S.D., T.-H.Y., Y.-H.Y.) and Department of Anatomy and Cell Biology (J.-H.L.), National Taiwan University Hospital and National Taiwan University College of Medicine, Taipei, Taiwan. function in patients treated with intratympanic gentamicin injection.

(Ear \& Hearing 2007;28;18-25)

Vestibular evoked myogenic potentials (VEMP) can be easily recorded from bilateral contracting sternocleidomastoid muscles by using loud sound stimulation (Colebatch, Halmagyi, \& Skuse, 1994) and has been validated to reflect the sacculo-collic reflex (Uchino, Sato, Sasaki, et al., 1997). In a recent study, we successfully recorded myogenic potentials in alert guinea pigs by using click stimulation that appeared to resemble human VEMP responses (Yang \& Young, 2005). Hence, this animal model sets the stage for studying toxic effects of aminoglycosides on the saccule.

Aminoglycosides are well known to cause ototoxicity, with differences between the sensitivities of cochlear and vestibular sensory cells (Aran, 1995; Halsey, Skjonsberg, Ulfendahl, et al., 2005). Among the members of the aminoglycoside family, gentamicin can selectively destroy human vestibular hair cells and thus severely impair vestibular function (Halmagyi, Fattore, Curthoys, et al., 1994). In contrast, amikacin or kanamycin is more cochleotoxic than vestibulotoxic. Consequently, intratympanic gentamicin administration has become the preferred treatment for intractable vertigo in cases of Ménière disease. Our recent study found that most patients $(67 \%)$ who had a Ménière attack had abnormal VEMPs, indicating that the saccule "participates" in a Ménière attack (Kuo, Yang, \& Young, 2005). Therefore, elimination of saccular function may prevent vertiginous attack. Although most studies have identified damage to the cochlear and vestibular end organs as the primary site of aminoglycoside toxicity, little attention has been devoted to the effect on the saccule. Recently, monitoring VEMP responses in patients with Ménière disease after intratympanic gentamicin injection revealed the absence of VEMP (de Waele, Meguenni, Freyss, et al., 2002; Picciotti, Fiorita, Di Nardo, et al., 2005). However, whether absent VEMP is due to Ménière disease itself (Young, Huang, \& Cheng, 2003) or to the gentamicin effect remains uncertain. Therefore, this study applied three kinds of aminoglycosides 
into the tympanic space of guinea pigs to examine the toxic impact on the saccule by way of clickevoked myogenic potential test coupled with morphologic assessment.

\section{Materials and Methods}

\section{Animal Preparation}

Randomly bred Hartley-strain female albino guinea pigs weighing 220 to $250 \mathrm{~g}$ were divided into 4 groups of 10 animals each. Each animal was treated with various compounds such as saline, gentamicin, tobramycin, or amikacin on the left ear; the right ear served as a control.

Under intraperitoneal pentobarbital sodium anesthesia, the left tympanic bulla was opened to expose the round window area (Young, Nomura, \& Hara, 1992). An amount of $0.05 \mathrm{~mL}$ of saline, gentamicin $(40 \mathrm{mg} / \mathrm{mL})$, tobramycin $(40 \mathrm{mg} / \mathrm{mL})$, or 0.16 $\mathrm{mL}$ of amikacin $(12.5 \mathrm{mg} / \mathrm{mL})$ was injected directly overlying but not through the round window membrane in each group, respectively. The rationale for the dosage selection was based on the use of 0.3 to $0.6 \mathrm{~mL}$ gentamicin for humans (Minor, 1999), with one tenth of this dose being administrated to the guinea pigs (Young, Chuu, Liu, et al., 2001). One week after surgery, each animal underwent auditory brain stem response (ABR), caloric test, and click-evoked myogenic potential test. This study was institutional review board approved and was conducted in accordance with the guidelines for the care and use of laboratory animals by the Animal Research Committee in National Taiwan University, College of Medicine.

\section{ABR in Guinea Pigs}

A pair of needle electrodes was placed on the vertex and ipsilateral retro-auricular region, and a ground electrode was placed on the neck of the guinea pig. Under intraperitoneal pentobarbital sodium $(35 \mathrm{mg} / \mathrm{g}$ ) injection, click stimuli (duration, 0.1 msec; frequency bandwidth, 1 to $4 \mathrm{kHz}$ ) were delivered through a plastic tube inserted into the ear canal to record ABR (Smart EP2, Intelligent Hearing Systems, Miami, FL). The repetition rate was $20 / \mathrm{sec}$, and an average of 400 sweeps was made. The stimulus intensity initially was $100 \mathrm{~dB}$ SPL, followed by 10-dB decrements until waveforms were no longer present, and thus determining the threshold of ABR. If no response was recorded at $100 \mathrm{~dB}$ SPL, an intensity of $135 \mathrm{~dB}$ SPL was used to confirm the absent ABRs.

\section{Caloric Test in Guinea Pigs}

The head and body of an alert guinea pig were restrained by a clamp; the four legs were left free. A pair of clip electrodes was attached to the canthi of both temporal orbits, and a reference electrode was attached to the vertex at the midline. The ear canal was irrigated with ice water $\left(0^{\circ} \mathrm{C}, 5 \mathrm{~mL}\right)$ for $5 \mathrm{sec}$, and the animal was put in a prone position. Recordings were made by using a two-channel electronystagmographic recorder (NY-13 Rion Co, Tokyo, Japan). To analyze the caloric nystagmus curve, the calibration of eye movement in electronystagmographic recordings was set at $5 \% 10 \mathrm{~mm}$. Both the caloric nystagmus and the slow phase velocity (SPV) of each derived caloric nystagmus were recorded. The mean SPV in controlled guinea pigs was $6.8 \pm$ $1.1 \%$ sec (mean $\pm \mathrm{SD}$ ). Animals with SPV exceeding $9.0 \%$ sec (mean $+2 \mathrm{SD}$ ) were classified as hyperactive response, whereas those with SPV below $4.6 \%$ sec (mean $-2 \mathrm{SD}$ ) were defined as canal paresis. Once there was no caloric response, the caloric test was repeated after a 5-minute interval (Young, Nomura, Okuno, et al., 1991).

\section{Click-Evoked Myogenic Potential Test in Guinea Pigs}

A clamp was applied to restrain the head and body of each test animal; the legs were left free. Each animal underwent VEMP test without anesthesia. A pair of needle electrodes was fitted on both dorsal neck extensor muscles of each test animal at the level of the third cervical vertebral bone (C3); a reference electrode was placed on the occipital area at the midline, and electromyographic activity was recorded (Smart EP2, Intelligent Hearing Systems, Miami, FL). During the recording, each animal was fixed with its head elevated and neck hyperextended in a prone position throughout the test. Electromyographic signals were amplified and bandpass-filtered between 30 and $3000 \mathrm{~Hz}$. Click stimuli (100 dB $\mathrm{SPL}$, duration $=0.1 \mathrm{msec}$ ) were delivered through an earphone connected through a short tube inserted into the bilateral ear canals. Monaural acoustic stimulation with unilateral recording was conducted. The stimulation rate was $5 \mathrm{~Hz}$ and the analysis time for each response was $24 \mathrm{msec}$, with 200 responses being averaged for each run.

Each animal underwent serial tests, with initial stimulus intensity of $100 \mathrm{~dB}$ SPL, followed by $10-\mathrm{dB}$ decrements until the absence of waveform, and the threshold was determined. The positive/negative polarities of biphasic waveforms were termed waves I and II, based on their latencies of approximately 7 msec and $9 \mathrm{msec}$, respectively. Consecutive runs 
were performed to confirm the reproducibility of peaks I and II; thus the click-evoked myogenic potentials were defined as present. Conversely, myogenic potentials were absent when the biphasic waveform was not reproducible. Subsequently, the latencies of positive peak I, negative peak II, and peak-to-peak I-II amplitude were measured for analyzing the responses (Yang \& Young 2005).

\section{Morphologic Assessment}

After deep anesthesia with $50 \mathrm{mg} / \mathrm{kg}$ intraperitoneal injection of sodium pentobarbital, the animals were perfused intracardially with saline solution followed by a fixative containing $2.5 \%$ glutaraldehyde in $0.1 \mathrm{~mol} / \mathrm{L}$ phosphate buffer at $\mathrm{pH}$ 7.4. After complete fixation, the animals were decapitated, and the temporal bones were harvested and placed in the same fixative for $24 \mathrm{hr}$, decalcified with $10 \%$ ethylene diamine tetra acetic acid (EDTA) containing 2.5\% glutaraldehyde at $\mathrm{pH} 7.4$ for $1 \mathrm{wk}$. The tissue blocks were cut horizontally into $200-\mu \mathrm{m}$ thickness slices with a vibratome and postfixed in $1 \%$ osmium tetroxide for $1 \mathrm{hr}$. The sections were dehydrated in ascending ethanol solution, infiltrated with propylene oxide, and finally embedded in Araldite-Epon mixture. Semi-thin $(1 \mu \mathrm{m})$ sections were cut with a Leica Ultracut E ultramicrotome (Vienna, Austria) and stained with toluidine blue for light microscopic study. For the electron microscopic study, ultrathin sections (60 to $80 \mathrm{~nm}$ ) of the specimen were cut and stained with $1 \%$ lead citrate and observed under an electron microscope (Hitachi 7100, Tokyo, Japan).

\section{Statistical Methods}

The response rates among various stimulus intensities were compared by Cochran $Q$ test. The correlations between the stimulus intensity and the latency or amplitude were analyzed by one-way analysis of variance tests. Abnormalities of ABRs, caloric responses, or click-evoked myogenic potentials between each group were compared by Fisher exact test. A significant difference indicates $p<0.05$.

\section{Results}

\section{Guinea Pigs Treated With Saline}

All animals treated with saline displayed normal ABRs, with a mean threshold of $39 \pm 8 \mathrm{~dB}$ SPL; normal caloric responses with a mean SPV of $6.8 \pm$ $1.1 \%$ sec; and normal click-evoked myogenic potentials with a mean threshold of $79 \pm 13 \mathrm{~dB}$ SPL (Fig.
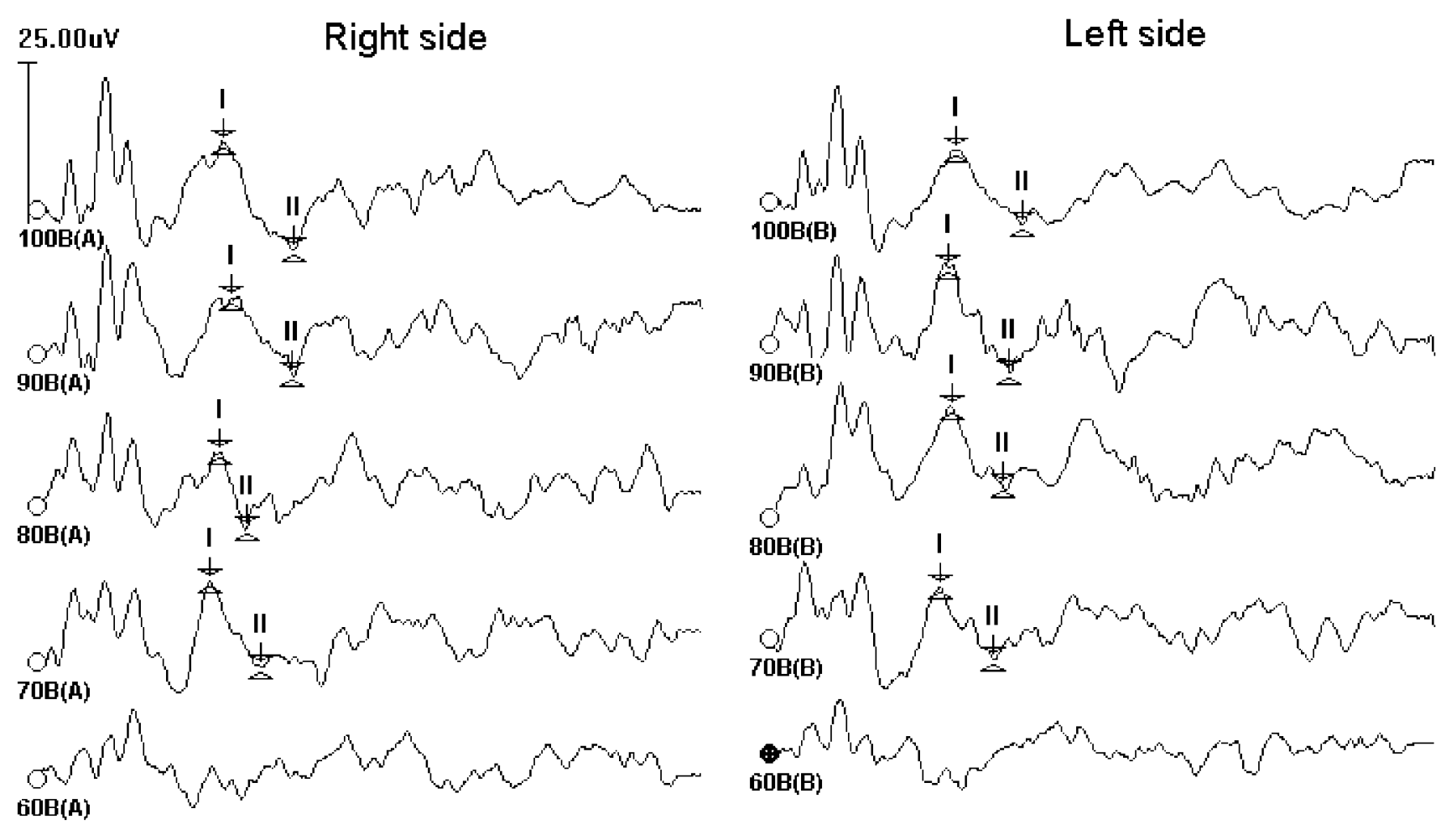

\begin{tabular}{lllllllll}
\hline 0 & 3 & 6 & 9 & 12 & 15 & 18 & 21 & $24 m s$
\end{tabular}

\begin{tabular}{lllllllll}
\hline 0 & 3 & 6 & 9 & 12 & 15 & 18 & 21 & $24 \mathrm{~ms}$
\end{tabular}

Fig. 1. Myogenic potentials (I, II) are present in a guinea pig through the use of click stimulation from 100 to $70 \mathrm{~dB}$ SPL. 
TABLE 1. Correlations of stimulus intensity with response rate, latency, or amplitude of click-evoked myogenic potentials in guinea pigs

\begin{tabular}{cccccc}
\hline $\begin{array}{c}\text { Stimulus Intensity } \\
(\mathrm{dB})\end{array}$ & $N$ (ears) & Response Rate & $\begin{array}{c}\text { Latency of Positive Peak } \\
\text { I (msec) (mean } \pm \text { SD) }\end{array}$ & $\begin{array}{c}\text { Latency of Negative Peak } \\
\text { II (msec) (mean } \pm \text { SD) }\end{array}$ & $\begin{array}{c}\text { Amplitude }(\mu \mathrm{V}) \text { Median } \\
(\text { Minimum-Maximum) }\end{array}$ \\
\hline 100 & 10 & $100 \%$ & $7.00 \pm 0.22$ & $9.21 \pm 0.38$ & $15.14(9.22-19.46)$ \\
90 & 10 & $80 \%$ & $6.89 \pm 0.25$ & $9.19 \pm 0.56$ & $12.19(8.66-24.07)$ \\
80 & 10 & $70 \%$ & $6.86 \pm 0.27$ & $8.76 \pm 0.48$ & $14.24(8.22-20.72)$ \\
70 & 10 & $60 \%$ & $6.80 \pm 0.30$ & $8.90 \pm 0.63$ & $11.00(7.01-23.00)$ \\
$p$ Value & & $p<0.05^{\star}$ & $p>0.05 \dagger$ & $p>0.05 \dagger$ & $p>0.05 \dagger$ \\
\hline
\end{tabular}

* Cochran $Q$ test.

tOne-way analysis of variance test.

1). The response rates of the myogenic potential elicited by $100,90,80$, and $70 \mathrm{~dB}$ SPL click stimulation were $100 \%, 80 \%, 70 \%$, and $60 \%$, respectively, demonstrating a significant relation between stimulus intensity and response rate $(p<0.05$, Cochran $Q$ test, Table 1).

The mean latencies of the positive peak I for click-evoked myogenic potentials in guinea pigs by using $100,90,80$, and $70 \mathrm{~dB}$ SPL click stimulation were $7.00 \pm 0.22,6.89 \pm 0.25,6.86 \pm 0.27$, and $6.80 \pm$ $0.30 \mathrm{msec}$, respectively. No significant relation was found between the stimulus intensity and the mean latency of the positive peak $(p>0.05$, one-way analysis of variance test, Table 1). Similarly, the stimulus intensity and the mean latency of the negative peak II were not significantly related $(p>$ 0.05 , one-way analysis of variance test, Table 1 ).

The peak-to-peak I-II amplitudes for the clickevoked myogenic potentials were $15.14 \mu \mathrm{V}$ (9.22 to $19.46 \mu \mathrm{V}$ ) [median (minimum-maximum)], $12.19 \mu \mathrm{V}$

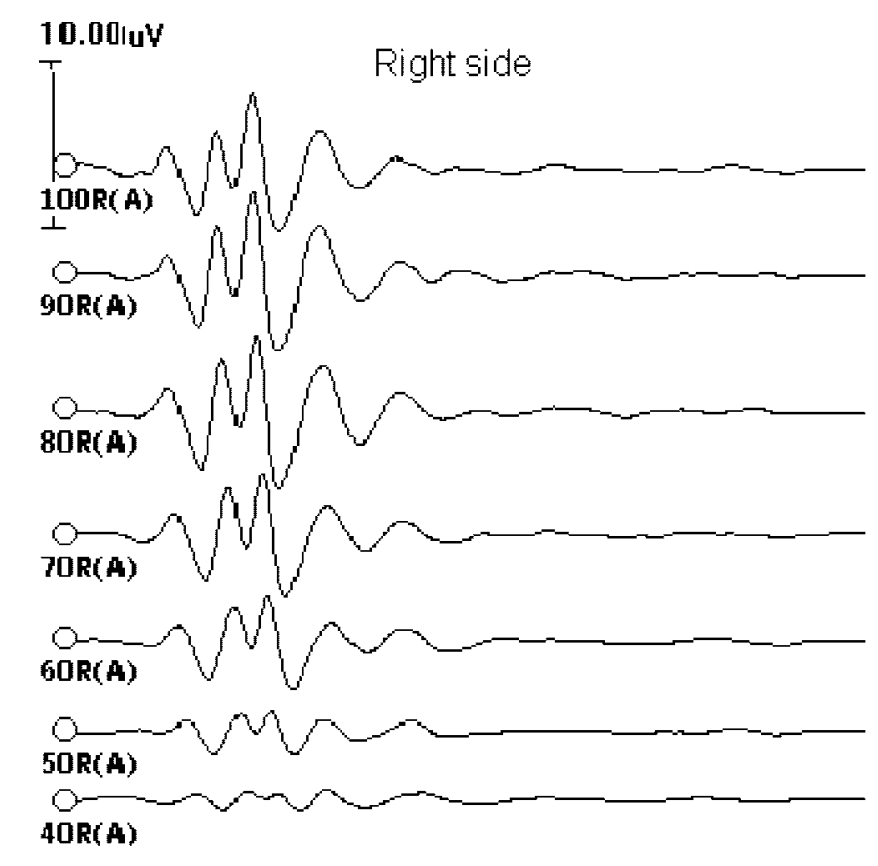

$\begin{array}{lllllllllllll}0 & 1 & 2 & 3 & 4 & 5 & 6 & 7 & 8 & 9 & 10 & 11 & 12 m s\end{array}$
(8.66 to $24.07 \mu \mathrm{V}), 14.24 \mu \mathrm{V}$ (8.22 to $20.72 \mu \mathrm{V}$ ), and $11.00 \mu \mathrm{V}(7.01$ to $23.00 \mu \mathrm{V})$, when elicited by 100,90 , 80 , and $70 \mathrm{~dB}$ SPL acoustic stimulation, respectively. The peak-to-peak amplitude of myogenic potentials did not decrease significantly when the stimulus intensity was attenuated from $100 \mathrm{~dB}$ to $70 \mathrm{~dB}$ SPL ( $p>$ 0.05 , one-way analysis of variance test, Table 1 ).

\section{Guinea Pigs Treated With Aminoglycosides}

To investigate the ototoxicity of aminoglycosides, guinea pigs were treated with various compounds through intratympanic application and then underwent ABR, caloric, and VEMP testing 1 wk after surgery.

ABR Changes $\bullet A B R$ displayed normal responses in 7 animals treated with gentamicin (Fig. 2) and elevated thresholds in the remaining 3 animals (30\%). In tobramycin-treated guinea pigs, all 10 animals (100\%) displayed abnormal ABRs, includ-
Fig. 2. Guinea pig treated with gentamicin on the left ear, $1 \mathrm{wk}$ after surgery. ABR reveals no elevation of the threshold bilaterally. 
TABLE 2. Comparison of audiovestibular deficits in guinea pigs treated with various compounds

\begin{tabular}{lcccc}
\hline & & \multicolumn{3}{c}{ Abnormality } \\
\cline { 3 - 5 } & & & Caloric & $\begin{array}{c}\text { Click-Evoked } \\
\text { Myogenic }\end{array}$ \\
Compounds & $N$ (ears) & ABR & Response & \begin{tabular}{c} 
Potentials \\
\hline Saline
\end{tabular} \\
Gentamicin & 10 & $0^{*}$ & $0 \dagger$ & $0 \dagger$ \\
Tobramycin & 10 & $3(30 \%)^{*}$ & $10(100 \%)$ & $10(100 \%)$ \\
Amikacin & 10 & $3(30 \%)$ & $4(40 \%) \dagger$ & $3(30 \%) \dagger$ \\
& & & $4(40 \%) \dagger$ & $4(40 \%) \dagger$ \\
\hline
\end{tabular}

${ }^{*} p>0.05$, comparison between saline and gentamicin groups, Fisher exact test.

$t p<0.05$, compared with gentamicin group, Fisher exact test.

ing elevated ABR threshold in 2 animals and absent ABRs in 8 animals. For those treated with amikacin, 7 animals had normal ABRs, whereas 1 had elevated ABR threshold and 2 showed absent ABRs (Table 2). Caloric Responses $\bullet$ Caloric tests revealed absent responses on the left (lesion) ears in all 10 animals $(100 \%)$ treated with gentamicin and revealed normal responses on the right ears (Fig. 3). In the tobramycin-treated animals, normal responses were demonstrated in 6 cases and abnormal responses in 4 cases (40\%), including canal paresis 2 and caloric areflexia 2. For the animals treated with amikacin, 6 animals showed normal caloric responses and 4 animals (40\%) displayed absent caloric responses (Table 2).

Click-Evoked Myogenic Potentials • All 10 gentamicin-treated animals (100\%) showed absent responses on the lesion side and normal responses on the control side (Fig. 4). In contrast, the animals treated with tobramycin or amikacin revealed absent click-evoked myogenic potential in $30 \%$ and $40 \%$ of cases, respectively (Table 2 ).
Comparison of the animals treated with saline, gentamicin, tobramycin, and amikacin intratympanically revealed abnormal rates for $\mathrm{ABR}$ in $0 \%$, $30 \%, 100 \%$, and $30 \%$ of animals; abnormal rates for caloric response in $0 \%, 100 \%, 40 \%$, and $40 \%$ of animals; absence of click-evoked myogenic potentials in $0 \%, 100 \%, 30 \%$, and $40 \%$ of animals, respectively. Significant differences existed between gentamicin and the other groups in abnormal rates of caloric responses and click-evoked myogenic potentials ( $p<0.05$, Fisher exact test, Table 2). However, abnormality of ABR between the gentamicin and saline groups did not differ significantly $(p>0.05$, Fisher exact test, Table 2).

\section{Morphologic Assessment in Gentamicin-Treated Animals}

To verify the absence of click-evoked myogenic potential originating from the saccular pathology, gentamicin-treated animals with absent click-evoked myogenic potentials were killed for morphologic assessment. Under light microscopic examination, the saccular macula of the control ear exhibited intact sensory and supporting cells covered by an otolithic membrane, which was a gelatinous mass with numerous small crystalline bodies, the otoliths (otoconia) (Fig. 5B). In the treated ear, the cell body of sensory cell in the saccular macula revealed atrophy and disruption, whereas the supporting cells, otolithic membrane, and otoconia were preserved (Fig. 5A).

Ultrastructurally, some sensory cells of the saccular macula in the gentamicin-treated ear displayed numerous vacuoles in the cytoplasm and became atrophied and distorted (Fig. 6A), in con-
Fig. 3. Guinea pig treated with gentamicin on the left ear, 1 wk after surgery. Caloric test reveals absent responses on the left (lesion) ear and normal response on the right ear. Upper tracing is the time base indicating 1 second per scale; middle tracing is the eye movement; lower tracing is the differentiated eye movement, clipped to show slow phase velocity. Arrow indicates termination of the caloric irrigation.

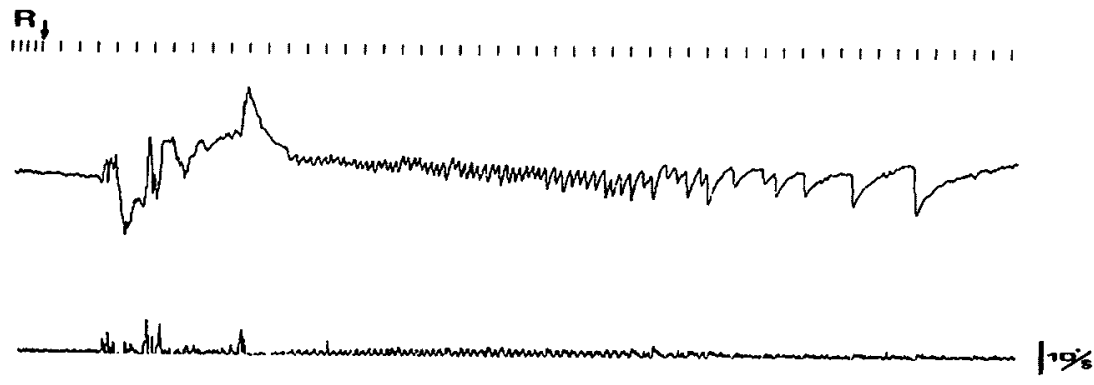

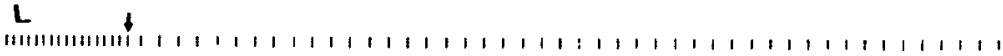



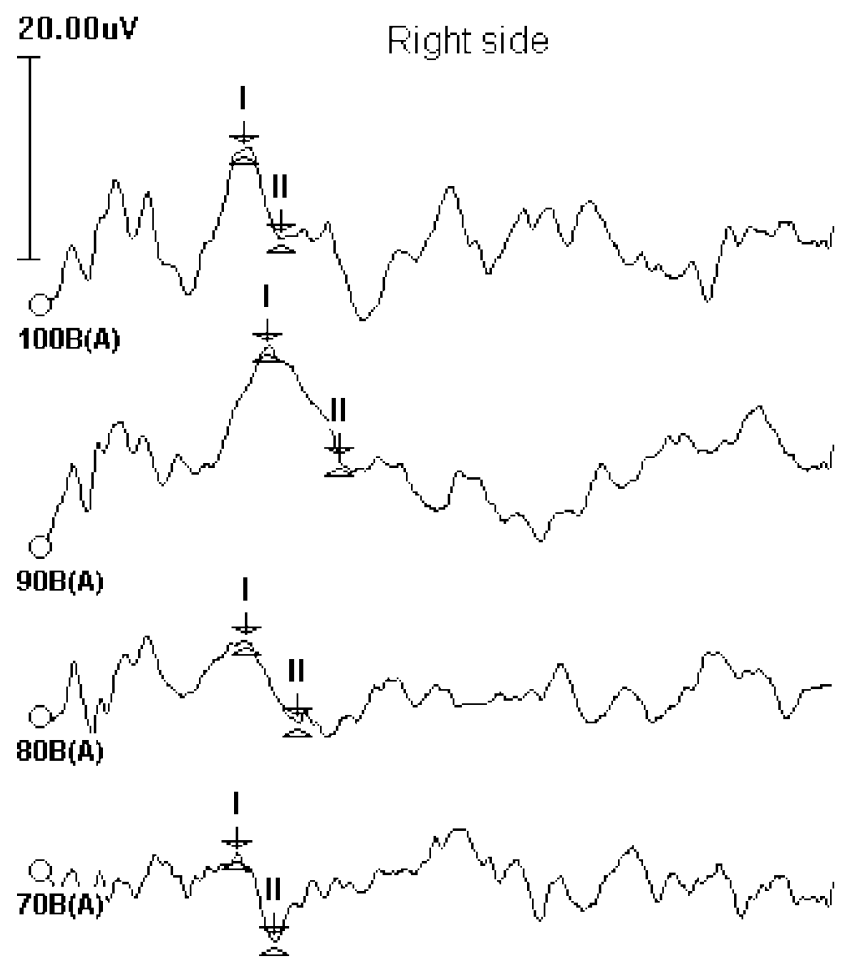

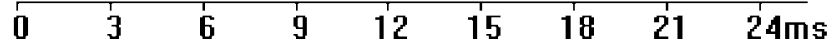

Fig. 4. Guinea pig treated with gentamicin on the left ear, $1 \mathrm{wk}$ after surgery. Click-evoked myogenic potentials are present on the control (right) side but absent on the lesion (left) side.

trast with the sensory cells of the control ear (Fig. 6B). The supporting cells, basement membrane, and vestibular nerve fiber remained intact in the treated ear.

\section{Discussion}

Intense sound and vibration have been reported to produce vestibular reflexes because the saccule of lower species such as amphibians and fishes can act as an acoustic receptor while vestibular fibers can also respond to sound (Cazals, Aran, \& Erre, 1980; Young, Fernandez, \& Goldberg, 1977). Accordingly, acoustically responsive saccular afferents trigger acoustic reflexes of the sternocleidomastoid muscle, and thus measuring such reflexes may provide a relatively simple test of saccular dysfunction (McCue \& Guinan, 1994). In guinea pigs, $40 \%$ of irregular discharging saccular afferents exhibited cochlear nucleus projections (Burian, Gstoettner, \& Zundritsch, 1989; Kevetter \& Perachio, 1989). It indicated that some cochlear efferent neurons collateralize within the vestibular nuclei. Murofushi, Curthoys, Topple, et al. (1995) reported that primary vestibular afferents, mostly of saccular origin, respond to loud clicks, with very short latencies and relatively high threshold in guinea pigs. This study therefore used guinea pigs stimulated by $100 \mathrm{~dB}$ SPL clicks to evoke myogenic potentials. This methodology offered a $100 \%$ response rate, with mean latencies of the positive I and negative II peaks being $7.00 \pm 0.22$ and $9.21 \pm 0.38 \mathrm{msec}$, respectively.

Instillation of gentamicin into the tympanic space has been reported to alleviate vertigo in patients with intractable Ménière disease, because gentamicin is relatively more vestibulotoxic than cochleotoxic (Minor, 1999), but its sacculo-toxic nature remains uncertain. Hence, in the current study, guinea pigs were treated with three kinds of aminoglycosides, namely gentamicin, tobramycin, and amikacin, through intratympanic application, to investigate their relative toxicity on the cochlear and vestibular end organs.

In guinea pigs treated with gentamicin on the left ear, the results showed that $70 \%$ of the animals had preserved ABR, but caloric responses and clickevoked myogenic potentials were absent in all 10 animals. Morphologic assessment by light and electron microscopic studies (Figs. 5 and 6) confirmed that the saccular pathology correlates with the absent click-evoked myogenic potentials in gentamicin-treated animals, further supporting the sacculotoxic nature of gentamicin. 

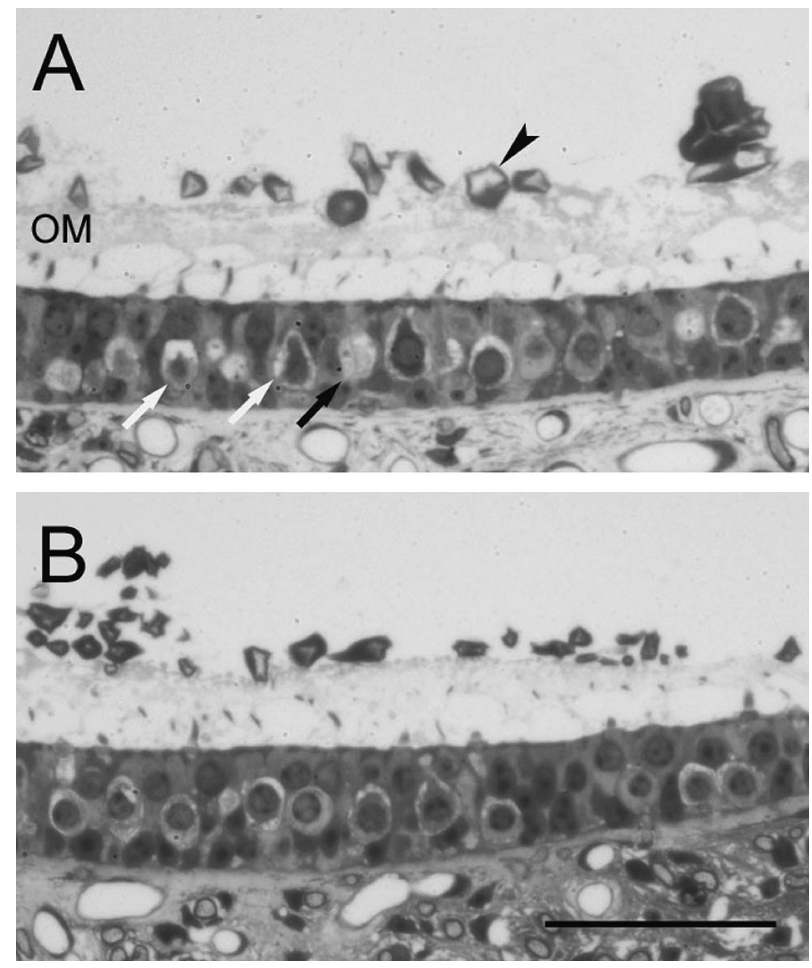

Fig. 5. Light micrographs demonstrate saccular macula on the treated (A) and control sides (B) in a guinea pig, 1 wk after gentamicin intratympanic injection. A, Irregular outlined and atrophic cell bodies of the sensory cells (white arrows) and lucent area (black arrow) between the sensory cells are noted in the saccular macula. Sensory cells are covered by an otolithic membrane (OM), which was a gelatinous mass with numerous small otoconia (arrowhead) (toluidine blue stain, scale bar $=40 \mu \mathrm{m})$.

In tobramycin-treated guinea pigs, all 10 animals exhibited impairment of cochlear function, including elevated ABR thresholds in $20 \%$ and absent ABRs in $80 \%$ of the animals. Conversely, abnormal caloric responses and absent click-evoked myogenic potentials had occurrence of $40 \%$ and $30 \%$, respectively.
The above indicated that tobramycin has selective cochleotoxicity, with less effect on the semicircular canals and saccule. In a human temporal bone study (Hinojosa, Nelson, Lerner, et al., 2001), two cases with long courses of tobramycin administration exhibited reduction of both hair cell and ganglion cell population of the cochlea, with sparing of the vestibular structure and Scarpa ganglion, consistent with our experimental results. Hence, tobramycin is ineffective for eliminating the saccular function.

Guinea pigs treated with amikacin revealed abnormal ABRs in $30 \%$ of cases, abnormal caloric responses in $40 \%$, and absent click-evoked myogenic potentials in $40 \%$ of cases, showing less toxicity than gentamicin, possibly because $0.16 \mathrm{~mL}(2.0 \mathrm{mg})$ amikacin locally applied onto the round window membrane is insufficient for abolishing both cochlear and vestibular functions in guinea pigs.

Accordingly, among the susceptibility of aminoglycoside-induced ototoxicity, gentamicin presents the most effective treatment for eliminating both semicircular canal and saccular functions, whereas little additional hearing loss is noted in patients with vestibular toxic reactions to gentamicin therapy (Dubie, Black, Pezsnecker, et al., 2006). In the current study, 30\% of the gentamicin-treated animals displayed elevated ABR thresholds when click stimuli with the frequency of 1 to $4 \mathrm{kHz}$ were used. The rate of $A B R$ abnormalities in gentamicintreated animals could be higher if click stimuli with higher frequencies were applied, because gentamicin damages the cochlea from the basal turn. Imamura \& Adams (2003) reported that single-dose application of gentamicin to the round window membrane of a guinea pig revealed a marked base-toapex gradient in cellular drug uptake, correlated with the gradient of cellular degeneration, which was most extreme at the cochlear base. Therefore, cochlear damage by gentamicin depends on local
Fig. 6. Electron micrographs demonstrate saccular macula on the treated (A) and control sides (B) in a guinea pig, $1 \mathrm{wk}$ after intratympanic gentamicin injection. A, Numerous vacuoles are shown in the cytoplasm of the sensory cell (arrow) on the treated side. B, On the control side, sensory cell (I) has a nerve chalice (arrowhead) that surrounds almost the whole cell. $S$ indicates supporting cells (lead citrate stain, scale bar $=4$ $\mu \mathrm{m})$.
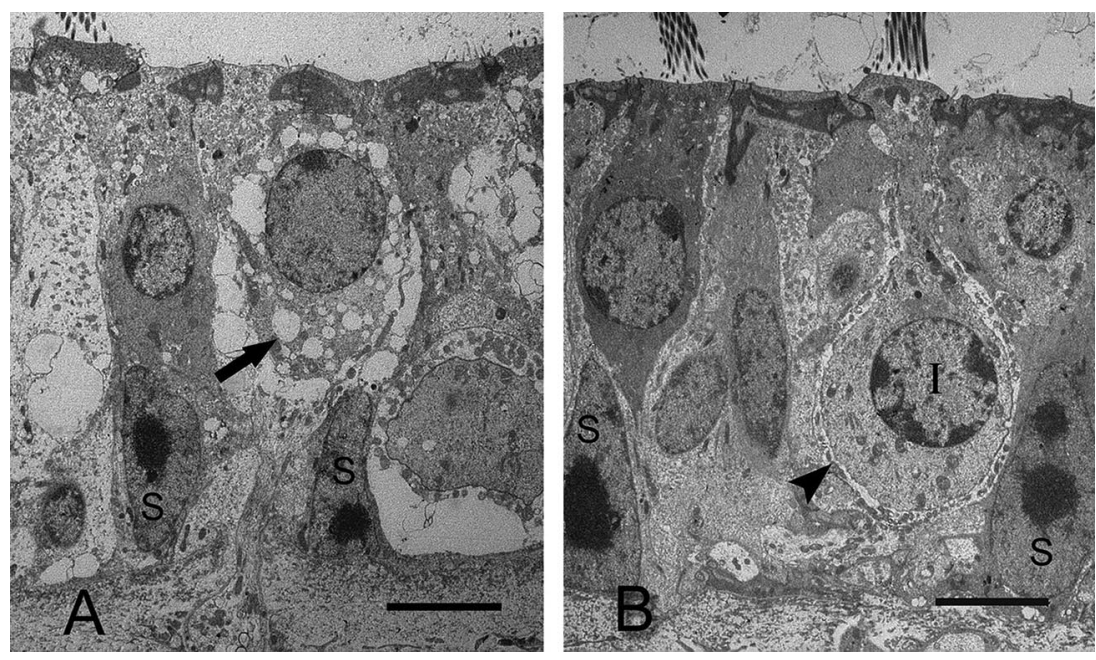
middle ear administration kinetics and total drug dosage (Wagner, Caye-Thomasen, Laurell, et al., 2005).

The elimination of saccular function is important for those patients with intractable Ménière disease undergoing intratympanic gentamicin injection because the saccule is the second most frequent site for the occurrence of endolymphatic hydrops (Okuno \& Sando, 1987). Although endolymphatic hydrops is an epiphenomenon of whatever causes Ménière disease, it does not have a cause-and-effect relation with a Ménière attack (Merchant, Adams, \& Nadol, 2005). This study further confirms the findings of human studies that the caloric and VEMP responses were monitored to assess the abolition of vestibular function in patients treated with intratympanic gentamicin injection.

\section{ACKNOWLEDGMents}

This work was supported by a research grant (NSC 94-2314B002-239) from the National Science Council, Taipei, Taiwan.

Address for correspondence: Dr. Yi-Ho Young, Department of Otolaryngology, National Taiwan University Hospital, 1 ChangTe St., Taipei, Taiwan. E-mail: youngyh@ha.mc.ntu.edu.tw.

Received December 4, 2005; accepted July 14, 2006.

\section{REFERENCES}

Aran, J. M. (1995). Current perspectives on inner ear toxicity. Otolaryngology Head and Neck Surgery, 112, 133-144.

Burian, M., Gstoettner, W., Zundritsch, R. (1989). Saccular afferent fibers to the cochlear nucleus in the guinea pigs. Archives of Otorhinolaryngology, 246, 238-241.

Cazals, Y., Aran, J. M., Erre, J. P. (1980). Acoustic responses after total destruction of the cochlear receptor: brainstem and auditory cortex. Science, $210,83-86$.

Colebatch, J. G., Halmagyi, G. M., Skuse, N. F. (1994). Myogenic potentials generated by a click-evoked vestibulocollic reflex. Journal of Neurology, Neurosurgery and Psychiatry, 57, 190197.

de Waele, C., Meguenni, R., Freyss, G., Zamith, F., Bellalimat, N., Vidal, P. P., Tran Huy, P. (2002). Intratympanic gentamicin injections for Ménière disease: vestibular hair cell impairment and regeneration. Neurology, 59, 1442-1444.

Dobie, R. A., Black, F. O., Pezsnecker, S. C., Stallings, V. L. (2006). Hearing loss in patients with vestibulotoxic reactions to gentamicin therapy. Archives of Otolaryngology Head and Neck Surgery, 132, 253-257.

Halmagyi, G. M., Fattore, C. M., Curthoys, I. S., Wade, S. (1994). Gentamicin vestibulotoxicity. Otolaryngology Head and Neck Surgery, 111, 571-574.

Halsey, K., Skjonsberg, A., Ulfendahl, M., Dolan, D. F. (2005). Efferent-mediated adaptation of the DPOAE as a predictor of aminoglycoside toxicity. Hearing Research, 201, 99-108.

Hinojosa, R., Nelson, E. G., Lerner, S. A., Redleaf, M. I., Schramm, D. R. (2001). Aminoglycoside ototoxicity: a human temporal bone study. Laryngoscope, 111, 1797-1805.
Imamura, S. I., Adams, J. C. (2003). Changes in cytochemistry of sensory and nonsensory cells in gentamicin-treated cochleas. Journal of the Association for Research in Otolaryngology, 4, 196-218.

Kevetter, G. A., Perachio, A. A. (1989). Projections from the sacculus to the cochlear nuclei in the Mongolian gerbil. Brain Behavior Evolution, 34, 193-200.

Kuo, S. W., Yang, T. H., Young, Y. H. (2005). Changes in vestibular evoked myogenic potentials after Ménière attacks. Annals of Otology Rhinology \& Laryngology, 114, 717-721.

McCue, M. P., Guinan Jr J. J. (1994). Acoustically responsive fibers in the vestibular nerve of the cat. Journal of Neuroscience 14, 6058-6070.

Merchant, S. N., Adams, J. C., Nadol Jr J. B. (2005). Pathophysiology of Ménière's syndrome: are symptoms caused by endolymphatic hydrops? Otology \& Neurotology, 26, 74-81.

Minor, L. B. (1999). Intratympanic gentamicin for control of vertigo in Ménière's disease: vestibular signs that specify completion of therapy. American Journal of Otology, 20, 209219.

Murofushi, T., Curthoys, I. S., Topple, A. N., Colebatch, J. G., Halmagyi, G. M. (1995). Responses of guinea pig primary vestibular neurons to clicks. Experimental Brain Research, 103, 174-178.

Okuno, T., Sando, I. (1987). Localization, frequency and severity of endolymphatic hydrops and the pathology of the labyrinthine membrane in Ménière's disease. Annals of Otology Rhinology \& Laryngology, 96, 438-445.

Picciotti, P. M., Fiorita, A, Di Nardo, W., Quaranta, N., Paludetti, G., Maurizi, M. (2005). VEMPs and dynamic posturography after intratympanic gentamicin in Ménière's disease. Journal of Vestibular Research, 15, 161-168.

Uchino, Y., Sato, H., Sasaki, M., Imagawa, M., Ikegami, H., Isu, N., Graf, W. (1997). Sacculocollic reflex arcs in cats. Journal of Neurophysiology, 77, 3003-3012.

Wagner, N., Caye-Thomasen, P., Laurell, G., Bagger-Sjoback, D., Thomsen, J. (2005). Cochlear hair cell loss in single-dose versus continuous round window administration of gentamicin. Acta Otolaryngologica, 125, 340-345.

Yang, T. H., Young, Y.-H. (2005). Click-evoked myogenic potentials recorded on alert guinea pigs. Hearing Research, 205, 277-283.

Young, E. D., Fernandez, C., Goldberg, J. M. (1977). Response of squirrel monkey vestibular neurons to audio-frequency sound and head vibration. Acta Otolaryngologica, 84, 252-260.

Young, Y.-H., Chuu, J. J., Liu, S. H., Lin-Shiau, S. Y. (2001). Toxic effect of potassium bromate and thioglycolate on vestibuloocular reflex systems of guinea pigs and human. Toxicology \& Applied Pharmacology, 177, 103-111.

Young, Y.-H., Huang, T. W., Cheng, P. W. (2003). Assessing the stage of Ménière's disease using vestibular evoked myogenic potentials. Archives of Otolaryngology Head and Neck Surgery, 129, 815-818.

Young, Y.-H., Nomura, Y., Hara, M. (1992). Vestibular pathophysiologic change in experimental perilymphatic fistula. Annals of Otology Rhinology \& Laryngology, 101, 612-616.

Young, Y.-H., Nomura, Y., Okuno, T., Hara, M. (1991). Clip electrode method for recording eye movements in experimental animals. European Archives of Otorhinolaryngology, 248, 331-334. 